\title{
\#FeesMustFall: Changing the Landscape of e-Assessment to Accelerate Connective Assessment Design for Sustainable e-Assessment in Higher Education
}

\section{Hermien Johannes \\ Simon Goldstone}

\begin{abstract}
The \#FeesMustFall disruptions at South African Universities have resulted in the application of a new approach to controlling the e-Assessment environment for formal summative assessments. The question to ask is: Do we have to control the environment? If yes, what if we can't do it in a traditional way? We argue that high-stakes assessments could be effectively controlled by purposeful design. The dynamic Connective Assessment Design (ConAD) model for e-Assessment in higher education could provide structure and direction, not only for formative, but also for high-stake summative eAssessment in higher education. This paper describes the conceptualisation, design and implementation processes, as well as examples of the application of the ConAD model for e-Assessment in higher education.
\end{abstract}

Keywords: e-Assessment, Connective Assessment Design Model, Higher Education, MOOCs (Massive Online Open Courses)

\section{Background}

Higher Education in South Africa has experienced student protests over a period of growing tension, before reaching breaking point in 2016, when campuses closed for an extended period, placing stress upon Institutions trying to complete the academic year and successfully to complete the final examinations.

Instances where examinations were deferred because of the impact of 
\#FeesMustFall (\#FmF) were reported (Heraldlive 10 January 2017). A lack of e-Assessment readiness from South African Universities resulted in various responses, which, if approached more systematically, could have minimised some of these disruptions. The Nelson Mandela University's response to the \#FmFdisruptions resulted in accelerated e-Assessment developments and practices. Technology-enhanced education and online methods of delivery were employed institutionally, across all faculties. These methods of delivery were supported by Academic Development staff from the Centre for Teaching and Learning, in order to enable the completion of the academic year and all associated activities. The Connective Assessment Design Model (ConAD) model was tested and refined in various contexts, such as research projects, teaching- and learning-funded projects, everyday teaching, learning and assessment practices, high-stakes tests and examinations, over a number of years. It was found that \#FmF accelerated the application of the model on all levels. The model was not developed in response to \#FmF. The impact of \#FmF created multiple opportunities to validate the ConAD model in authentic contexts.

Over time, various descriptions of e-Assessment reflected its dynamic nature in a fast-changing world. For this discussion, e-Assessment refers to technology-supported/enhanced-online assessment. The e-Assessment extends over a range of assessment contexts, purposes, designs, processes and applications. These could include online formative, summative or connected assessments. E-Assessment was developed over the years from drill and practice on computers in laboratories for formative-mastery learning and summative tests towards assessments, as part of tutorials, class tests, examinations or highstakes e-Assessment for certification in controlled environments such as examination centres. Therefore, formal e-Assessment for high stakes assessment requires extensive preparation and monitoring to create secure physical spaces, sufficient computers, invigilators, support staff and IT specialists, as well as the infrastructure to conduct these assessments. According to Crown (2007: 6),

effective e-Assessment practice should be guided by a number of essential success factors. These include consistent and reliable processes; skilled staff to manage and deliver these processes; practitioner accountability; and flexibility to implement change, in response to technological improvements. 
The reasoning behind setting-up secure environments is to control, secure and to minimise cheating and dishonest assessment practices. Therefore, the suitability of traditional assessment control measures in connective assessment inspired us to think differently about e-Assessment. The ConAD model provides a framework for connective assessment, in which the locus of control has moved from physical environments and people to assessment design and the application of online-design models.

The importance of these came to the fore during the \#FmF protests; and this contributed to the acceleration of changing e-Assessment practices, to set principles and guidelines to support the assessment processes, and to include the participation of the various role-players at the Nelson Mandela University. It is worth noting that the demands placed on ICT service roleplayers, from engineers to administrators, necessitated the formation and the implementation of creative solutions, with respect to remote networks, data access and secured communications.

During the \#FmF shutdown, a part of the academic completion plan included having classes, in addition to the December and January exams at the Nelson Mandela Bay stadium. The ICT Services had to set up a computer laboratory containing general use personal computers, as well as specialised ones. ICT Services were also tasked to design and develop a security check-in system to be used at the stadium gates, in order to ensure that only Nelson Mandela University students, invited for that specific day, were allowed entry. The system was designed to be efficient and fast at the check-in points. This was done through the development of a back-end application that does all the business-process checks, imports, queries and reporting.

The new interim lecture timetable with reduced teaching time drove the demand for changing practices and accelerated technology adoption. Online or e-Assessment supported by the Moodle-Learning Management System (LMS) became integral to the assessment practice.

The increased utilisation of the LMS with respect to access, performance and the changing requirements for e-Assessment tested all the aspects of the system's various capabilities. In total, nearly 50000 check-ins were recorded as part of the access and utilisation of the temporary campus for the completion of academic and examination activities.

Off-campus teaching, learning and assessment activities resulted not only in changes in approaches and practices; but it also provided opportunities to implement and test the ConAD model, to address some of the e-Assessment 
challenges. These included design specifications and format settings for offcampus assessment in uncontrolled environments for summative tests and examinations. The assessment design included a number of design specifications for each step in the assessment process, linked to the assessment purpose and the desired outcomes. Therefore, within the unfamiliar \#FmF context, multiple opportunities could be utilised to think out-of-the box and to test and apply the ConAD model.

The difficult question to answer remained: 'How do we secure eAssessment to protect the integrity of the assessment and to promote ethical conduct?' To address some of the challenges, e-Assessment became the focal point and a prominent driver in the assessment of the student learning system. Collaboration between Faculty, e-Assessment and Moodle specialists, supported by the Dean of Teaching and Learning, the Centre for Teaching, Learning and Media, as well as ICT services, resulted in various e-Assessment pilot projects. In addition to these, the existing Teaching Development and Innovation funded projects, initiatives by faculties, departments, individual staff members and the Blended Learning Team culminated in the successful implementation of summative e-Assessment and the examination of student learning during the 2016 and the 2017 academic years.

While setting up the remote assessment laboratories, valuable experience was gained in the development of the required and accompanying guidelines and procedures for the correct deployment of e-Assessment activities in the interim period. It is important to note the significance of the sequence of events for conducting summative e-Assessments. For example, before a summative assessment is administered, the module design must allow opportunities for a developmental approach, in order to move from entry into the course, to formative assessment for learning, as a prerequisite for the summative assessment of learning, ultimately to include the connective assessment that is learning. The e-Assessment process starts with the preparation of students and staff on many levels, for example, insuring that students have access to the system (Salmon 2004), providing sufficient instructions for the required actions, e.g. for completing online activities, such as tutorials and formative assessments, as well as the training of staff and students, in order to optimise their user experience.

Guiding/scaffolding students into a formative, non-threatening mastery learning environment (Padayachee, Johannes \& Wagner-Welsh 2018: 221 ) is an essential step in the process to develop the required technical skills, 
and to align the teaching, the assessment design, the activities and the outcomes. The next step is to introduce a form of summative e-Assessment to prepare the students for the final e-Examination. A LMS, such as Moodle, is paramount for such an e-Assessment. Being open sourced, customisable, fit for purpose, it provides a competitive advantage over other e-Assessment and learning-management systems. The Moodle environment is perfectly suited for fine-tuning the assessment-design specifications, system behaviour, assessment settings, and for hosting large question banks. Advanced settings for design, delivery, implementation, feedback, reports, gradebooks and management provide a customisable enriched e-Assessment environment. Furthermore, various question types are available; and these must be suitable for eAssessment applications. For example, the Stack question type, which adds sophisticated assessment in mathematics and related disciplines with the emphasis on formative assessment is underpinned by computer algebra.

Several Nelson Mandela University projects, spanning diverse disciplines, contributed to the corpus of e-Assessment knowledge, informed practice and theory and inspired prototyping. These projects provided a framework; and they paved the way, for the conceptualisation of the ConAD model for sustainable e-Assessment in higher education. The dynamic, changing higher educational environment in 2016 - 2017 provided opportunities to move beyond the conceptualisation, prototyping and testing of the ConAD model to the actual design, development, implementation and evaluation phases. The application of the ConAD model assisted the decision-making processes regarding best practices for the different assessment contexts, outcomes, formats and applications. Furthermore, the model provided the theoretical and conceptual frameworks to guide instructional design, as well as the paradigmatic choices for e-Assessment.

Examples of these are customised design specifications for application within mastery-learning contexts, controlled assessment environments, or connected assessment networks. Connective assessment includes the self-, peerand the expert assessment of student learning within a connected network environment. The connective assessment network may include other connected network - and assessment environments, including people e.g. course facilitators, subject experts, and students, professional learning networks; online courses e.g. MOOC's; formal and informal online courses, as well as the resources for teaching, learning and assessment e.g. open-online repositories and course-related resources. The application of the ConAD model aims 
to address some of the design challenges associated with the summative eAssessment of student learning. The purpose of the model is to provide a framework for system and design thinking, decision-making and for the instructtional design choices for authentic e-Assessment in a connective assessment environment, in order to meet the demands of higher education. In the next sections, these will be briefly illustrated within the connected-world context.

\section{The Reality of the Connected-World}

Why is it important to think differently about e-Assessment in higher education? The connected technology-driven world of work, social and personal contexts has changed the way people learn, communicate, manage their lives and do their work. Openness, internet access, the availability of resources, media, technologies and personal devices have all contributed to ondemand personalized teaching and learning. The completion of work tasks has moved towards collaborative, team, and specialised project approaches. Consequently, teaching, learning and assessment in higher education should respond accordingly, in order to remain relevant and on-the-cutting edge. Over time, accelerated by the \#FeesMustFall events, and the real-world contexts, these issues have inspired us to think differently about the design for authentic and connective assessment - in order to mimic real life. We concur with Eric Mazur, who emphasises that 'We must rethink assessment. If we fail, we will continue to educate the followers of yesterday, instead of the leaders of tomorrow'. Consequently, the assessment of student learning should focus on skills, rather than on content (Mazur 2017).

We have moved away from trying to control and secure the physical formal assessment environment to control by setting the assessment-design specifications for purposeful assessment design, including the development and the implementation thereof. Therefore, we have changed our thinking to conceptualise, develop and implement an innovative, unique ConAD model. This model, operating within a connected environment, has been successfully applied in various contexts, utilising a selection of technologies, to address some of the difficulties that go with traditional, secured, controlled, bound-bylocation and space, assessments.

The traditional assessment theory and practice focus on atomised approaches, based on objective assessment practices, in controlled environments. James (2017: 406) has refined three clusters of learning theories: the 
behaviourist, constructivist and sociocultural approaches into a typology that highlights the evolution of assessment practices. For example:

(1) Behaviourist drill and practice, tutorials and practice tests;

(2) Constructivist approaches, where students create their own meanings, which could be assessed by self-, group-, and peer assessment techniques; and

(3) 'Assessment that is more coherent with a transactional view of learning, i.e. between actor and social structure (Vygotsky 1978 in James 2017: 408).

James (2017: 408 - 409) highlights the following in this regard: assessment should be situated; it should be done by the community rather than by external assessors; the assessment of group learning is thus important.

The use of examination centres and designated venues is common practice for conducting high-stakes examinations and tests. The approach to control high-stake assessment is rooted in the belief that one should test the level of knowledge and understanding regarding specific concepts, problems or occurrences, in order to grade the students' competencies, in a strictly controlled environment. This is the common practice. We agree that there is a time and place for these types of assessment. However, we propose that teaching, learning and assessment theories that are rooted in behaviourism, constructivism and cognitivism are only partly sufficient in the connected modern wold of today. What is required is citizens who are capable of thinking critically and able to provide creative solutions to world problems. Therefore, to be able to achieve this, one of the important skills is to know where to find trustworthy information, how to determine what is trustworthy, and how to apply the chosen information to real-world problems in a variety of scenarios.

Therefore, not only are skillsets different from what was required in the past; but we also need to know how these skillsets are to be judged, assessed, or evaluated. New ways of doing and thinking regarding student assessment of learning are required. Therefore, assessment practices should change to suit the requirements of today's world. The use of authentic assessment approaches is advocated as a possible application/ approach. Although we agree that authentic assessment approaches are suitable as possible assessment applications, most of these scenarios are still bounded by outdated views on assessment. 
A fourth cluster of learning theories, namely connectivism, should be added to James' (2017) typology, in order to highlight the evolution of assessment practices. Our view is that in our connected networked world, creative problem-solving and the assessment of learning should be underpinned by the beliefs and theories of connectivism. Connectivism assumes that everything is connected in various networks, containing a varied number of nodes. According to Julia Layton, the core of connectivist theory states that 'In the digital age, learning happens most effectively in networks'. Siemens said, it is exponentially increased by the act, and the art, of collaboration (Layton 2013). Martin Weller (2018), in his synopsis of the last twenty years of educational technologies, highlights the following time periods, as important milestones in the development of connectivism:

2004 - 2005: George Siemens and Stephen Downes proposed connectivism; and these two could lay claim to being the first internetnative learning theorists. Siemens defined connectivism as 'the integration of principles explored by chaos, networks, complexity and self-organization theories. Learning is a process that occurs within nebulous environments of shifting core elements, which are not entirely under the control of the individual' (Siemens 2004; Downes 2005).

2012 (MOOCs) Inevitably, 2012 will be seen as the year of MOOCs (Pappano 2012). In many ways, the MOOC phenomenon can be viewed as the combination of several preceding technologies: some of the open approaches of OER, the application of video, the experimentation of connectivism, and the revolutionary type of web 2.0. The raised profile of open education and online learning caused by MOOCs may prove to be beneficial in the long run.

Goldie refers to connectivism as 'one of the most prominent of the network learning theories which have been developed for e-Learning environments' (Goldie 2016: 1064). Siemens (2005) lists the following principles of connectivism as being:

- Learning and knowledge reside in the diversity of opinions.

- Learning is a process of connecting specialized nodes or information sources. 
- Learning may reside in non-human appliances.

- It includes the capacity to know more; and this is more critical than what is currently known.

- Nurturing and maintaining connections is needed to facilitate continual learning.

- The ability to see connections between fields, ideas, and concepts is a core skill.

- Currency (accurate, up-to-date knowledge) is the intent of all Connectivist-learning activities.

- Decision-making is in itself a learning process. Choosing what to learn and the meaning of incoming information is seen through the lens of a shifting reality. While there is a right answer now, this may be wrong tomorrow, due to possible alterations in the information climate that would affect the decision.

Goldie (2016: 1069) states that 'in the connectivist model, the learning community is described as a node, which is always part of a larger network. Nodes may also be organisations, libraries, web-sites, journals, databases or any other sources of information' (Siemens 2006). Networks comprise two or more nodes, which are linked in order to share resources. They may be of varying size and strength, depending on the concentration of information and the number of individuals navigating through a particular node (Downes 2007). Successful networks are considered to have the following characteristics (Downes 2006; 2012):

- Diversity - the widest possible spectrum of the various points of view;

- Autonomy of the participants;

- Openness - mechanisms, which allow perspectives to be entered into the system; and

- Connectivity - connections between its nodes.

Goldie (2016: 1069) states that according to Siemens (2006), 'Connectivism is a conceptual framework, which views learning as a network phenomenon that is influenced by technology and socialization'.

'Connectivism views knowledge as sub-symbolic, with meaning arising from the interaction of sets of connections, rather than from single symbolic units' (Downes 2006; 2012). According to Comer and White (2016), 
MOOC's provide a paradigm where students 'hold the authority to define, construct, dismantle and redefine their own frameworks and parameters for assessment, learning, competency, success and failure'. We concur with Comer and White (2016) that there is 'the need to place assessment in the hands of learners themselves, in order to construct, develop, and experiment with assessment (Comer \& White 2016: 348).

The MOOC type relevant for this discussion is connectivist MOOC's, where the students actively collaborate to create and share knowledge (Xiong \& Suen 2018: 243). In our view, this feature is core within the connected assessment environment. The main considerations regarding MOOC design are highlighted as pedagogical, resources and logistical considerations. The various types of student assessment and assessment design were mentioned as the main design challenges (Zhu, Bonk \& Sari 2018: 215); Xiong and Suen (2018: 244), 248; Goldie (2016:1069). Xiong and Suen (2018: 203 - 241) mentioned the various types of student assessment and the assessment methods as obstacles for assessment design. Xiong and Suen also highlight this (2018: 244) by stating: 'Although MOOC's provide a good platform to promote interaction, the assessment of student learning is a crucial challenge'. They concluded that 'peer assessment is quite possibly the only universally applicable approach in MOOC's (2018: 244). It is important to note that the teaching and learning context of our study differs from contexts, in which the emphasis is on professional development or registration. One may take a different approach to secure the assessment environment; as the aim is professional certification, which is different from the authentic real-world assessment of student learning, where the assessment simulates real-world scenarios. Assessment designs differ in terms of purpose, outcomes, tasks, contexts, grading and processes. One shoe does not fit all; what we propose is that connective assessment IS learning.

Although Xiong and Suen (2018: 215) are of the opinion that peer assessment is generally formative, our ConAD model includes peer assessment as a summative application as well. Peer assessment methods in MOOC's received considerable attention. Some authors (Xiong \& Suen 2018: 251) are concerned about the accuracy of peer assessment, and the loss of facilitator control (Goldie 1069). Other concerns are the overuse of automated grading (Zhu, Bonk \& Sari 2018: 215) and the cost of human-proctoring assessment, which is regarded as a last resort for a one-time summative assessment (Ebben \& Murphy 2014). According to Xiong and Suen (2018: 245) 'peer assessment 
remains key; and it is the most versatile approach for formative and summative assessment in open online education'.

In the connective assessment environment, peer assessment is a viable option. Automated processes and available tools in learning-management systems, e.g. Moodle's workshop tool provides sophisticated settings for peer, self, facilitator and expert assessments.

It is important to note that the ConAD model includes formative, summative, connective, peer, self and expert-assessment applications. Our view of connective assessment includes various networks and nodes, for example:

- people e.g. online facilitators, students, experts, assessors;

- resources e.g. open source repositories, databases, online libraries, books, journals, internet;

- assessment systems to include different assessment designs, purposes, applications, types such as -self, -peer, -expert and system assessment, programmes, tools and technologies, question banks;

- online teaching and learning environments, e.g. LMS's, such as Moodle, social-media platforms, online teaching and learning spaces, tools and technologies.

\section{The operating principles are:}

The Connective assessment of student learning is self-regulated within an assessment system that is design-controlled by paradigm-specific design features, such as time settings and scaffolding. Students' selection of networks and nodes is by their own choice. This is an important feature; and it is in contrast with what is presented as a challenge for peer /expert assessment in the literature. Various authors (Zhu \& Bonk 2018; Xiong \& Suen 2018) mention the set-up of peer assessment as a challenge and an overwhelming task for the facilitator; and furthermore, automated options, such as humanproctoring assessment is expensive; and it is regarded as a last resort for a onetime summative assessment (Ebben \& Murphy 2014).

People are interconnected; and when they are confronted with a problem, or task to complete, they would - in conjunction with their own expertise, knowledge and skills - use all the resources available to them (people, books, reports, internet, technologies and tools) to solve the problem or to complete the task. Therefore, why should we then stick to outdated assessment practices, far removed from reality? Students should be able to use 
all the available resources to complete a task. An assessment of their competencies, knowledge and skills should resemble the real-world context, and not an artificially controlled environment, which 'tests' a very small component of competency when solving a problem.

\section{This brings us to the following questions:}

- But is this the students' own work?

- How do we make sure that it is?

- We have to control the environment, in order to make sure that the students don't 'cheat'! Is asking for help from a colleague cheating in the real world?

- What are we assessing?

- Did the student master a specific chunk of information?

- Could this have been Googled?

- Could the student ask for help from a friend or an expert in the field; or was it copied from a book, or the internet?

\section{All these questions bring us to a few related ones, such as:}

- How should we design the question we want to ask the student to answer?

- Do we provide opportunities for students to develop their skills, in order to make sense of the overwhelming amount of information available?

- What is true?

- What should be believed as to be the truth?

- What should students memorize, practice or label as the correct answer to a question?

Within this complex environment with more questions than answers, how do we then assess students' learning?

From what we have learned from our research, practices and experience in this field, we propose that,

(1) assessment design should include authentic assessment tasks;

(2) the context should be an open-connected environment, with access to all the resources, people and technologies; 
(3) assessment design should include different approaches to suit the purpose of the assessment, e.g. mastery learning on the one hand (behaviourist) and a connectivist approach on the other side of the continuum.

The connectivist approach makes provision for various networks and nodes in the networks. The operating principles in this connected assessment system are time- and assessment-design features. The ConAD model is a replication of our thinking in this regard; and it guides assessment design for the authentic assessment in different contexts, for different purposes, and for application in a connected world.

The ConAD model provides theoretical and conceptual frameworks for decision-making regarding e-Assessment design. Which of these would help us answer the questions that became prominent during \#FmF. For example - How do we secure e-Assessment in a connected world, in order to protect the integrity of the assessment, and to promote ethical conduct? Could we include peer and expert reviewers for summative online assessment?

\section{The ConAD Model is Underpinned by the Following Theories of Learning and Assessment}

Mary James (2017: 405) discusses the meaning of 'learning' in assessment of/for/as learning. She quotes Baird et al. (2017), stating that 'theories of learning and assessment should be developed more closely with each other; if such assessments are to serve the goals of education. Moreover, this should not only apply to everyday assessment in the classroom by teachers, but also to high-stakes, large-scale assessments in education'. Therefore, 'assessment researchers need to engage more with educators and learning theories and vice versa' (James 2017: 405). Assessment and learning theories, and associated pedagogies, such as behaviourism (drill and practice, mastery learning), constructivist (constructing own learning) informed practice (James 2017, 405). More recently, connectivist theories are being aligned with teaching, learning and assessment theories and associated self-directed/determined learning (heutagogy), where the learners are the problem finders (Richardson, McGowan \& Styger 1840).

George Siemens described connectivism 'as a learning theory for the digital age' (Siemens 2005). With reference to the principles of connectivism 
related to the assessment of learning, he states that the focus is on the 'recognition of expertise by other participants inside the network' (Halfanhour blogspot 2014/04). Although peer assessment is mentioned as an option for connected environments (Zhu, Bonk \& Sari 2018; for Xiong \& Suen 2018), the Connective assessment theory is still in its infancy stage. We propose that the ConAD model may contribute to developing this field. We propose that instead of trying to put new wine into old bags, we should rather think differently about connective assessment. The Connective assessment theory is embedded in connectivism and related heutagogical approaches.

\section{ConAD Model Principles}

The 'ConAD model is underpinned by the learning and assessment theories of connectivism and the mastery learning approaches supported by informed practice, in order to conduct successful assessments of student learning - be it continuous, formative, summative or connective' (Goldstone, Johannes, Terblanche \& Meyer 2017: 44).

\section{Other important principles of the ConAD model are as follows:}

- The quality educational design is based on the priorities of the networks e.g. autonomy, diversity, openness and interactivity.

- Students use their internal processes to activate learning through a series of nodes originating from the lecturer (Siemens 2005). In addition to the nodes originating from the lecturer, nodes in the network selected by the student would also include people e.g. experts in the field, peers, and support staff, networked resources, and various technologies and tools.

The ConAD model for networked assessment and grading (to connect, to enrich, to authenticate, to construct, to problem-solve, to grade, to evaluate, to benchmark) described here, not only includes the above-mentioned principles, but also the networks of people, including peers, lecturers and students, technologies, resources, and digital environments on various levels of openness. These are strengthened by the principles of assessment, eAssessment, mastery learning and self-directed learning.

Mastery learning, as proposed by Bloom in 1968, assumes that students would be able to master content and 'would be able to achieve a high 
level of understanding in a given domain; provided they are given enough time' (Anderson 1975). Therefore, tutorials and practice tests supported by informative feedback, rich resources and numerous opportunities to attempt the assessments are formative in nature; and these would contribute to student learning. However, summative assessment has as its various grades to make assumptions about learning. References to assessment in the context of connectivism are mostly referred to as self-, peer-, lecturer and expert assessment. Siemens (2005) highlights the importance of the recognition of expertise and peer assessment within the connected network. The term 'Connective assessment' selected as a descriptor in our ConAD model, is not used in the literature, as such. We have broadened the concept of Connective assessment networks to include the nodes of people, resources, systems, platforms, technologies, tools and design aspects. Design aspects may include the principles of self-, peer-, and automated assessment within a variety of contexts and networks. This conceptualisation of Connective assessment, supported by the theoretical underpinnings and principles from connectivism, mastery learning and e-Assessment have provided the foundation for the ConAD model for e-Assessment. The model provides a design framework for the Connective assessment design, development, implementation and evaluation processes. This implies that the design principles for an application within a mastery learning context would be linked to mastery learning principles, and also to the connective applications linked to connectivism and heutagogy.

For example, tutorial design for mastery learning applications would allow for unlimited time, attempts and excellent feedback for the purpose of formative assessment for learning. Connective assessment, on the other hand, may require a short-time allowance and other design settings to contribute to an authentic assessment opportunity that simulates real-world scenarios.

It is important to note that the assessment purpose and placement on the mastery learning - Connective assessment design continuum informs the design specifications for the assessment. Design specifications may include the following: the assessment environment; -tasks; -format; -question types; instructions; -delivery mode; -tools; -settings; reporting and management. These are embedded in the following assessment principles, namely: constructive alignment, timeframe; flexibility; diversity; inclusiveness; selfmanagement; autonomous; authentic; sustainable. These could contribute to the unique characteristic of the ConAD model discussed here. 


\section{The ConAD model includes the following characteristics:}

- Connective assessment is the recognition of expertise by other participants inside the network e.g. peers and experts in the field (as proposed by Siemens 2005).

- Connective-assessment-design maintains the locus of control within its design purpose.

- The Connective-assessment-design model is underpinned by learning and assessment theories of connectivism, heutagogy, assessment design and mastery learning approaches.

- The Connective-assessment-design model represents a living, dynamic system.

- The Connective-assessment-design model is rooted in a mastery learning - connective assessment continuum.

\section{ConAD Model Features}

Based on the above-mentioned characteristics of the ConAD model, the main features on the mastery learning connective assessment continuum may include:

- Authentic - real-world reflection, mimic problem solving.

- Connective - networked nodes of people, technologies, resources, digitally linked, online, open book, open access, dynamic, a continuum of controlled and uncontrolled designs, environments and contexts. Controlled by paradigm-specific design features e.g. limited time for connective assessment or extended /unlimited time for mastery learning.

- Assessment - authentic / real-world, problem-solving, opportunities, activities and tasks.

- e-Assessment design - assessment principles e.g. fairness, reliability, validity, aligned with purpose, teaching strategies and learning outcomes.

- Approach - authentic task design in real-world contexts, focusing on skills, competencies and application, and not so much on content. The approach is knowledge-building and problem-solving, using mastery- 
learning approaches on the one side of the continuum towards selfdirected learning within connected networks and nodes.

- The operating principles include:

- Time allowance is a core-operating principle for:

- Connective assessment - which includes openness to utilise all the available resources e.g. peers, experts, online resources, networks and nodes to provide a solution to the problem / or the scenario (crowd-sourcing for solutions). Control by limited assessment timeframes and test times. This includes lecturer-, peer-, system- and self-assessment. The aim of the assessment is learning.

- Mastery learning allows open, unlimited time and attempts, provide excellent feedback, and require high grades to move to the next levels. The aim is to build knowledge, skills and to provide practice tests and tutorials. Control by pace, to allow for the achievements of high grades supported by feedback. The aim is the assessment of and for learning.

- Design principles

- The mastery learning approach is informed by the behaviouristparadigm specific design features.

- The Connective assessment approach is informed by the connectivist-paradigm specific design features.

- The e-Assessment design is informed by authentic assessmentparadigm specific design features.

- The heutagogical learning design is informed by the learning theories for self-determined learning-design features.

- Teaching and learning principles for constructive alignment between teaching, learning, assessment and leaning outcomes.

- The context may include controlled, semi-controlled, open, and uncontrolled environments.

- Purpose - formative, summative, connective, peer-, and self-assessment.

The ConAD model shows the relationships between the important components, within the connected environments and the various contexts. 
In the next section, the ConAD model's characteristics and features are illustrated by examples of the ConAD model in diverse applications.

\section{Illustrated Model Examples}

It is important to note that the ConAD model is a living, dynamic system. Therefore, the components, characteristics, features, input elements, processes and output, feedback loops and outcomes may vary, according to the nature of the dynamic network of nodes, as defined by the assessment context, purpose, assessment characteristics, opportunities, activities, tasks, and time allocations embedded in a continuum of assessment approaches. The operating principle and control mechanism is the purpose and assessment timeframe and time allocation. The assessment-design specifications and the time-slider on the continuum would activate the appropriate network nodes and the connections appropriate for the selected assessment-design features. Therefore, the behaviour of the assessment is controlled by setting the pace and setting the design specifications within a networked, connected environment. As conducting high-stake examinations in secured physical environments are becoming difficult to sustain, the alternative of authentic, secured by purposeful design, e-Assessments is becoming a sustainable reality.

The ConAD model features are displayed in Figure 1. The design model shows the relationships between the important components, within connected environments and contexts. The various assessment components are staggered at the base; and they include the context, the purpose of the assessment, as well as the assessment opportunities, activities and tasks. Basic assessment-design components form the foundation of the model. The context may range from uncontrolled, open environments, to semi- and fullycontrolled environments. The e-Assessment of student learning may include one or more purposes, for example, formative, summative, connective, peerand self-assessment. The connective network includes, but not exclusively, people, technology, online, resources, security, system settings, learning outcomes, navigation, problem-solving, professional-learning networks, communication, and platform nodes.

The approach continuum separates the base from the network of nodes above. The assessment purpose and placement on the continuum informs the design-specific settings and the design blueprint; and in turn, the variables above. The aim of applying the model is to control by purposeful design. 
\#FeesMustFall: Changing the Landscape of e-Assessment

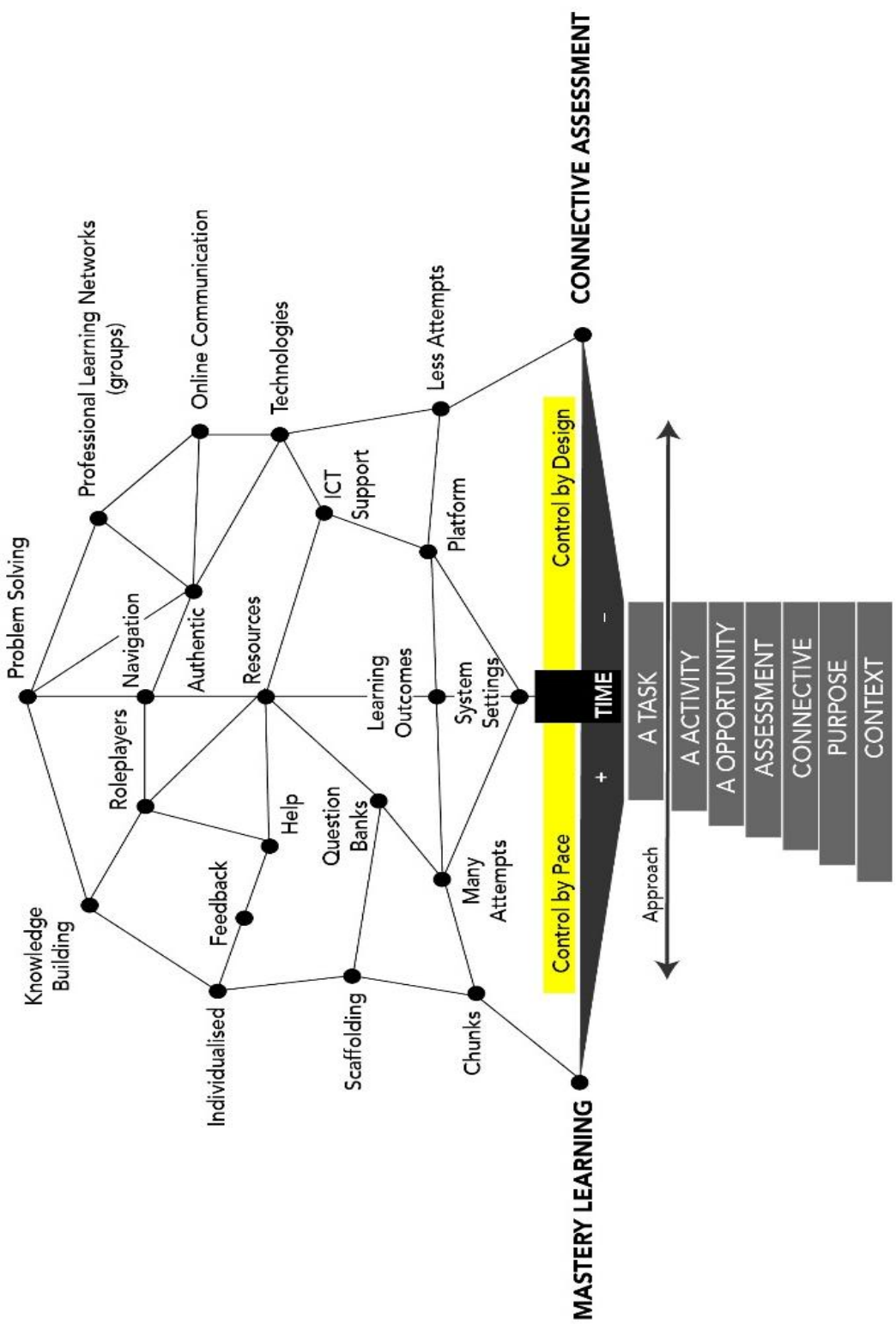

Figure 1: ConAD model features 


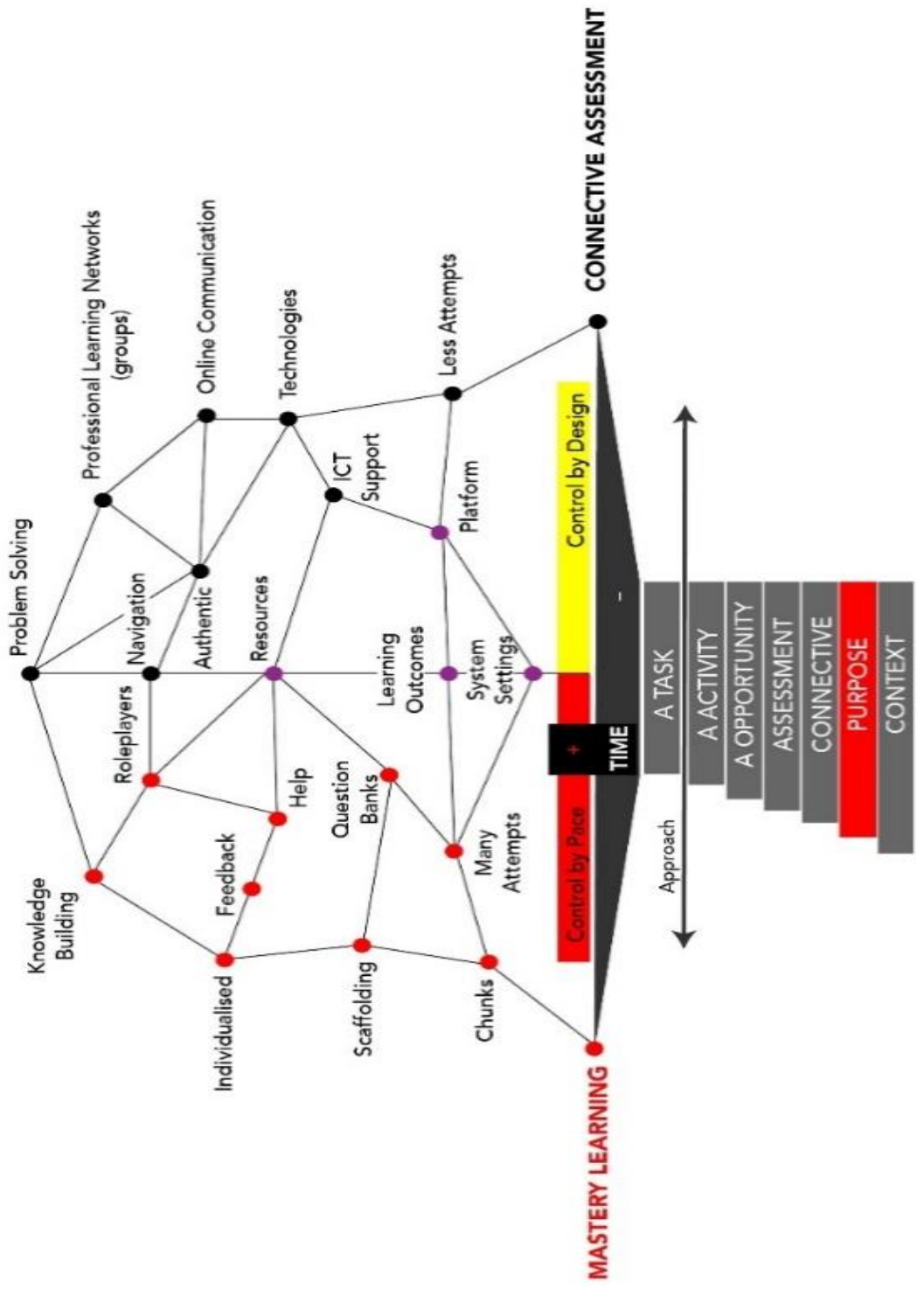

Figure 2: ConAD model features in an open-mastery learning environment controlled by pace and scaffolding 
Figure 2 shows an example of the ConAD model in an open mastery learning environment controlled by pace and scaffolding as the design specifications. This would activate the appropriate network nodes and the connections appropriate for the selected mastery-learning assessment design. Important features to promote mastery learning and formative assessment are practice tests/tutorials, drawing various question types from large question banks, multiple attempts, no time limit, self-paced learning, excellent formative feedback to enhance learning, multiple resources, chunks of information presented, high-grade achievement to move to the next level, scaffolded learning enabled via available checkpoints, peer and lecturer support, as well as input.

The implications of this approach are the assessment of learning in an enriched, networked environment of people, resources, and non-threatening self-paced e-Assessments.

\section{The implications for educators and assessors are as follows:}

- The model is for broader design (specifications) and the implementation (blueprint) of online assessment.

- The model is for the initial conceptualisation of online assessment.

- The design process identifies and defines the relevant elements and characteristics related to the nature of the desired assessment.

- The initial design paradigm is focused on mastery learning.

- The purpose is the assessment for and of learning.

Model features displayed in the centre of the network include the core of the model, namely: the system settings, learning outcomes, resources, navigation, the principles of assessment and problem-solving. The assessment purpose could vary from formative, summative, peer-, or self-assessment.

The key concept in this context is 'mastery' (James 2017: 410). Progression is not a linear approach; and Vygotsky advanced the view that the mastery of tools and the mind takes place in the zone of proximal development (James 2017: 408). 'Scaffolding and formative assessment are the strategies that teachers use to move learning forward in the zone of proximal development' (Shepard 2005: 66). The mastery-learning approach is ideally suited for linking formative assessment and feedback to scaffold student learning. 
According to Mary James (2017), in her 'Reviewing Assessment: Changing Lenses to Refocus on Learning, Assessment in Education: Principles, Policy \& Practice', the 'Scaffolding Theory' was first introduced in 1978 by Lev Vygotsky (1896 - 1934) (See also Wikipedia - Scaffolding Theory).

Assessment conversations between students and their teachers and peers can deepen their understanding of what counts as appropriate responses to problems or tasks, i.e. what counts as appropriate responses to tasks and problems i.e. what counts as quality and how the criteria for judgements are interpreted and applied in complex activities (James 2017: 410).

On the other end of the Connective assessment design continuum, the connective assessment design includes authentic assessment in a network controlled by purposeful design features.

Figure 3 shows an example of the ConAD model in a connective assessment environment controlled by design. The time slider moved on the time continuum towards control by design in terms of shortening the time allocation for assessments and limit attempts to one, or occasionally to two. This would activate the appropriate network nodes and the connections appropriate for the selected connective assessment design. Important model design features to promote connective assessment and summative, authentic assessment are the nodes of people (peers, experts, professional learning networks), technologies, online communication and the resources for openbook, online resources, ICT support, adequate infrastructure, platforms, devices and networks. System settings include no feedback regarding the students' answer responses and grades. The question design is aimed at problem-solving in authentic scenario settings. Navigation is set to the sequential mode, which prohibits going back to the questions and answers that were submitted. The reasoning behind these settings and a time limit is to use the design features to ensure that the student who is well-prepared would be able to complete the work in the set time.

Students who are not well-prepared would not have enough time to crowd-source the required information from the available resources. The implications of this approach are that assessment is learning in a rich, networked environment with authentic, real-world scenarios. 
\#FeesMustFall: Changing the Landscape of e-Assessment

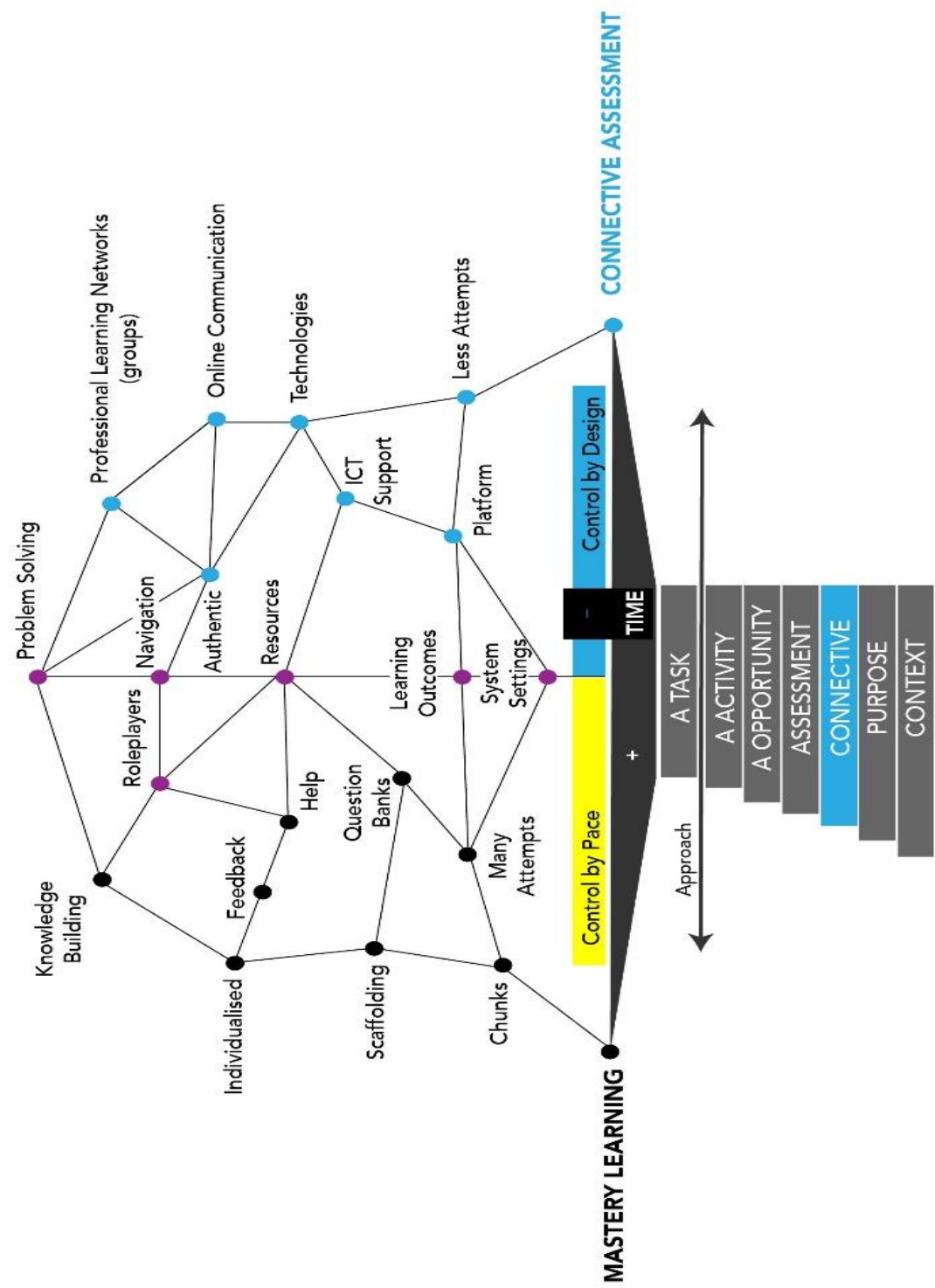

Figure 3: ConAD model features in a Connective assessment environment controlled by design 
The model features in the centre of the model include the core, namely: the system settings, learning outcomes, resources, navigation, the principles of assessment and problem-solving. The assessment purpose could vary from formative, summative, expert, peer or self-assessment. The implications for educators and assessors are that:

- As the student progresses to the summative assessment level, the context changes.

- The design changes from a mastery-learning approach to a connective assessment approach.

- A different set of elements with different characteristics with different patterns and relationships to determine the different outcomes, are accommodated.

- The design paradigm is focused ultimately on connective assessment.

- The purpose is authentic learning and assessment.

Examples to illustrate the model features in connected environments, include continuous e-Assessment in an uncontrolled environment, an open book-online formal semester test, and an open book-online examination.

\section{Continuous e-Assessment in an Uncontrolled Environment}

A large student group enrolled for a module in Numeracy Skills, and they had completed the full spectrum on the approach continuum. The students were introduced to online mastery learning tutorials, completed a formal semester test in a controlled environment, and continuous e-Assessment in an open, uncontrolled environment. These replaced a final examination in a controlled environment. The design settings for online mastery learning tutorials included unlimited resources and attempts at one's own pace, a pass mark of 75\%, as a prerequisite for the next assessment. The next formal assessment opportunity included a semester test in a controlled environment. Design settings for this assessment included one attempt, within a set timeframe, no additional resources, and password protection, secured login in a controlled computer laboratory. Connective e-Assessment contributed to the final grade to pass the module. Important control design specifications included sequential navigation, $75 \%$ to pass, one attempt within a time limit, randomized system generated Stack type questions drawn from a large question bank (see Figure 
4). Automated grading, reports, and grade-book streamlined the e-Assessment process. Important control design features are informative, clear instructions to students (see Figure 5); students must be familiar with e-Assessment system behaviour features too, such as sequential navigation (see Figure 6), which prohibits going back to a previously answered question and limited time to complete the assessment.

The rationale for the time limit is to minimize the opportunities to 'phone a friend', 'ask the expert', 'google the answer', and work together in groups. In some instances of self-, and peer-learning and assessment, the time limit is set to accommodate the purpose of the assessment. See examples (Figures 4 to 6) of design specifications for continuous e-Assessment in an uncontrolled environment.

\section{Stack question example}

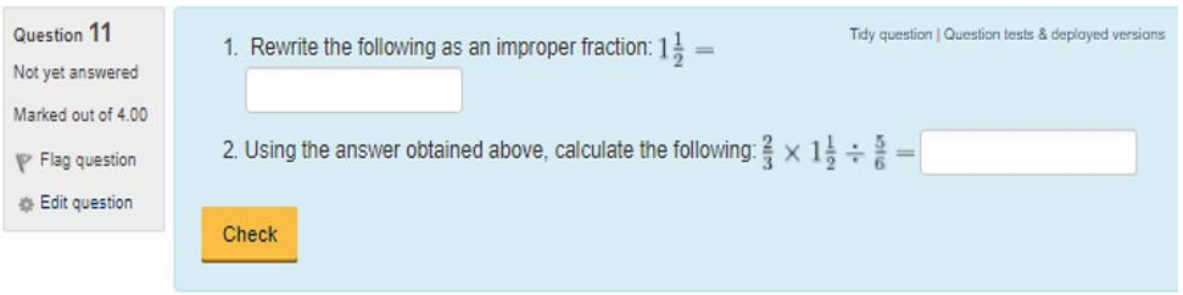

\section{Figure 4: Example of Stack question type in Moodle}

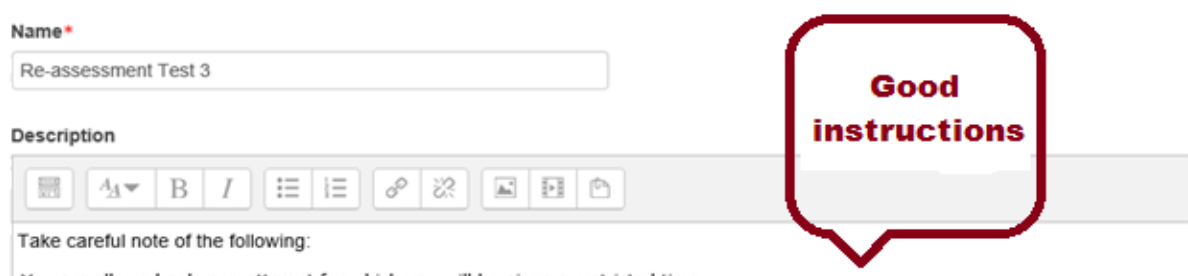

You are allowed only one attempt for which you will be given a restricted time.

Make sure that before you start the assessment everything is in place. For example make sure that your device is fully charged, you have the best internet connection and that you will not be interrupted.

You will need to answer the test questions in the order given. You will not be able to skip questions and then go back to them again. You will not be able to move back to questions. Once you have attempted a question it will be submitted. Remember to click the 'check box' when a check box is presented.

\section{Figure 5: Informative instructions to students}




\section{- Layout}

New page (?)

Every question

Navigation method*

Sequential

Show less..

- Question behaviour

Shuffle within questions

Yes $\checkmark$

How questions behave

Deferred feedback

Figure 6: Moodle assessment system behaviour settings, such as sequential navigation

\section{Open Book-online Formal Semester Test}

We illustrated the prominence of the time setting as a directive design specification in the ConAD model. The next example shows the fundamental importance of question design for authentic e-Assessment. Also, the features of an open book-online formal semester test taken by third-year Social Science students illustrate this point. The timeframe for the assessment was set for oneand-a half days; and the time allocated for the assessment was 150 minutes. When the time expired, the system automatically submitted the answers and closed the assessment. 


\section{- Timing}

Open the quiz

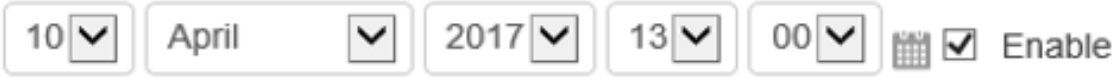

Close the quiz

\begin{tabular}{|c|c|c|c|c|c|}
\hline $11 \checkmark$ & April & $\checkmark$ & $2017 \checkmark$ & $2 3 \longdiv { V }$ & $00 \checkmark$ 的 \\
\hline
\end{tabular}

\section{Time limit}

150 minutes $\checkmark \checkmark$ Enable

\section{When time expires}

\section{Open attempts are submitted automatically}

\section{Figure 7: Assessment system behaviour settings for timing}

The question design included a variety of scenarios with added questions, presented randomly, as essay-type questions. The students had to personalize their answers with information drawn from their portfolios that they had developed during the year. For example:

'Use the approaches that you were introduced to in this module and assess this family. Incorporate factors from the ...'.

Although the assessment was set up, as open book, open access with unrestricted online resources, their own portfolios compiled during the semester, were used as primary resources and the quality of these was reflected in their performance. 


\section{Open-book Online Examination}

The third example illustrates the application of the ConAD model to design, implement and evaluate an open book, online, any device, any location examination for a large group of students. Congruence and alignment between teaching and assessment practices are fundamental for successful e-Assessment. In preparation for the examination, the required sequence of events included the preparation of students by offering multiple online engagements with their Moodle site to complete low-stake assessments and tasks, and to participate in online communication and activities. Furthermore, informative written instructions for required actions and tasks and adequate technical and administrative support from various role-players, were in place. Most important for the successful implementation of open book, online examinations, is good communication and planning between the lecturer and the students, support staff from ICT services, the Blended-Learning team, and staff from Faculty. Although the students could freely select their examination location and devices, alternatives were available to those students, who preferred to utilise the university's computer laboratories, venues, computers, networks and WiFi.

The ConAD model provided structure and guidance for the design, implementation, evaluation and reflection processes linked to the open-book e-Examination placed on the far end of the Connective assessment continuum. Sophisticated assessment settings in Moodle contributed to a refined, customised, fit for purpose e-Examination opportunity. The features included in the design are:

- Time-settings appropriate for completing the required tasks.

- Within the timeframe, the students had to complete three sections presented separately.

- Each section contained a question set of the same question type, e.g. a section consisting of two authentic case studies, randomly presented to complete in essay format. The second section contained a large question bank of multi-choice questions, from which six were randomly presented. The third section contained a number of short paragraph-written answer questions.

- Free navigation was allowed.

- The assessment settings were tested and refined by a team consisting of the lecturer and her colleagues, the Blended-Learning team, ICT services support and staff from the examination office. 
- The Moodle system behaviour was monitored throughout the implementtation phase.

- The lecturer was available online during the duration of the examination to answer questions, and to act as an online invigilator.

\section{What are the Lessons Learnt for the Way Forward?}

The important lessons learnt are:

- A multi-disciplinary team approach.

- Training, support and guidance to staff and students to utilise and benefit from the available e-Assessment environments, technologies and tools.

- Collaboration between all the role-players.

- Mainstream integrated e-Assessment available to all the students.

- e-Assessment structures and processes to be in place, e.g. ICT infrastructure, Moodle platform well-resourced and supported.

- Infrastructure, delivery, and implementation support for all the relevant role-players.

- A unified and co-ordinated approach. Such an approach would speed up the implementation processes; and it would provide a consistent user experience.

- Policy development regarding e-Assessment, blended / digital learning, Moodle, and educational technologies.

- Specific guidelines and procedures to support these policies.

\section{Implications for Higher Education}

Why is the ConAD model important for higher education? The dynamic model provides a framework for system design thinking to set the appropriate blueprints and specification lists for customisable, authentic assessment design for application in a variety of contexts, domains and disciplines in higher education. Subsequently, informing assessment development to create opportunities for solving real-world problems, within an authentic assessment focus, to foster 21 st century skills and competencies. Therefore, grading becomes incompatible with real problem-solving (Mazur 2017). The blueprint for e- 
Assessment design should be supported by the relevant assessment, e-Assessment, online/ blended learning policies and guidelines. A holistic institutional approach to align the above-mentioned with inter-related institutional procedures and policies, such as examination-, academic integrity-, teaching and learning- and moderation policies and procedures, are of the utmost importance.

Furthermore, the e-Assessment system and Moodle LMS capabilities are the main features in the successful application of the ConAD model.

Kellen $(2017,50)$ is of the opinion that the importance of the LMS is fading in the Edtech ecosystem. This might be the case in a teaching and learning ecosystem, where the educational tools require a great deal of tailoring (Kellen 2017 53). We are of the opinion that assessment cannot be separated from authentic teaching and learning, given that this is an integrated process within a holistic approach.

The requirements for e-Assessments are determined by the context, purpose, approach etc. which demand set conditions. The LMS environment could cater for most of these. Development regarding the next generation LMS ecosystems is strongly focused on the essential attributes for the nextgeneration digital learning environments, in order to deepen learning (Adams Becker, et. al. 2017: 8). One of these is learning assessment. The Educause Learning Initiative research into the next generation digital-learning environment identified the 'enabling role of technologies to relate assignments to real-life application' and 'the growing focus on measuring learning' (Adams Becker et al. 2017: 8) as a mid-term trend for the next three to five years. This trend highlights the interest in assessment of student learning. It is clear that 'universities must rethink how to define, measure, and demonstrate subject mastery and soft skills, such as creativity and collaboration' (Adams Becker et.al. 2017: 8).

Application of the ConAD model bridges the traditional approaches to e-Assessment; and these trending aspirations are described in the Horizon Report 2017 (Adams Becker et al. 2017: 2) to prepare students for the $21^{\text {st }}$ Century workplace.

The application of the ConAD model would require a connected ecosystem, including subsystems, such as an LMS and assessment ecosystems that are sophisticated and refined to provide the necessary features and setting options to customise and develop fit-for-purpose e-Assessment opportunities,. The powerful assessment features in an LMS, such as Moodle, provide these. 
Discussions regarding LMS's are mostly focused on features for enhancing teaching and learning; but as we pointed out above, the future of higher education lies in authentic assessment to cater for the demands of the $21^{\text {st }}$ century. The role of the LMS is vital in providing a structured platform for creating, hosting, managing, monitoring and analysing authentic and purposeful e-Assessments.

The assessment ecosystem is an integral part of teaching and learning; and as such, it cannot be separated therefrom. The power of e-Assessment in the digital teaching and learning ecosystem is therefore of the utmost importance; and it should be prioritised, as a dynamic force and a strategic priority.

\section{Summary}

We are optimistic that the ConAD model could contribute to the authentic eAssessment design for sustainable assessment in higher education in order to ultimately address the challenges in the reality of the connected world. This model provides theoretical and conceptual frameworks for decision-making regarding e-Assessment design within the context of authentic and measurable e-Assessment.

In an increasingly connected world, with new and diverse tools and sources of information, the future of e-Assessment seems less likely to focus on the control of the traditional elements within the electronic environment. The success of Connective assessment lies in the purposeful design and implementation of both planned constraints and provisioned resources. With application for formative to summative e-Assessment, the ConAD model and assessment design approach is positioned to deliver real-world-aligned and ultimately authentic assessments, mapped into the online space.

\section{References}

Adams Becker, S., M. Cummins, A. Davis, A Freeman, C. Hall Giesinger \& V. Ananthanarayanan 2017. The New Horizon Report 2017 Higher Education Edition. Austin, Texas: The New Media Consortium.

Anderson, L.W. 1975. Major Assumptions of Mastery Learning. Annual Meeting of the Southeast Psychological Association. Available at: https://eric.ed.gov/?id=ED150172 (Accessed on 10 January 2018.) 
Biggs, J. 1996. Enhancing Teaching through Constructive Alignment. Higher Education 32: 347 - 364. Available at:

https://doi.org/10.1007/BF00138871

Comer, D.K. and E.M. White 2016. Adventuring into MOOC Writing Assessment: Challenges, Results, and Possibilities. College Composition and Communication 67,3: 318 - 359. Available at:

http://www.ncte.org/library/NCTEFiles/Resources/Journals/CCC/0763feb2016/CCC0673Adventuring.pdf (Accessed on 9 April 2019.)

Crown Copyright 2007. Extract on page 6 from e-Assessment. Guide to Effective Practice. Qualifications and Curriculum Authority. London. Available at:

https://www.e-assessment.com/wp-content/uploads/2014/08/eassessment_-_guide_to_effective_practice_full_version.pdf (Accessed on 30 January 2018.)

Downes, S. 2005. An Introduction to Connective Knowledge. December 22, 2005. Available at: https://www.downes.ca/cgi-bin/page.cgi?post=33034 (Accessed on 9 April 2019).

Downes S. 2006. Learning Networks and Connective Knowledge. Available at: http://itforum.coe.uga.edu/paper92/paper92.htlm (Accessed on 9 April 2019.)

Downes S. 2007. An Introduction to Connectivist Knowledge in Hug T. Media, Knowledge \& Education - Exploring New Spaces, Relations and Dynamics in Digital Media Ecologies. Proceedings of the International Conference, June 25-27, 2007.

Downes S. 2012. Connectivism and Connective Knowledge. Essays on Meaning and Learning Networks. Available at:

https://www.downes.ca/files/books/Connective_Knowledge19May2012.pdf

Downes, S. 2014. Connectivism as a Learning Theory. Available at: http://halfanhour.blogspot.de/2014/04/connectivism-as-learningtheory.html

Ebben, M. \& J.C. Murphy 2014. Unpacking MOOC Scholarly Discourse: A Review of Nascent MOOC Scholarship. Learning, Media and Technology 39:328 - 345. Available at:

https://doi.org/10.1080/17439884.2013.878352

Goldie, J.G.S. 2016. Connectivism: A Knowledge Learning Theory for the Digital Age? Medical Teacher 38,10: 1064 - 1069. 
https://doi.org/10.3109/0142159X.2016.1173661

Goldstone, S.P., H. Johannes, K. Terblanche \& S. Meyer 2017. \#FeesMustFall: Changing the Landscape of e-Assessment. Book of abstracts. $11^{\text {th }}$ Southern Hemisphere Conference on the Teaching and Learning of Undergraduate Mathematics and Statistics. 26 Nov/01 Dec 2017 Gramado, Brazil. Available at:

https://www.univates.br/media/evento/delta/book_of_abstracts_final_08-11.pdf (Accessed on 10 January 2018.)

James, M. 2017. Reviewing Assessment: Changing Lenses to Refocus on Learning. Assessment in Education: Principles, Policy \& Practice 24,3: $404-414$.

https://doi.org/10.1080/0969594X.2017.1318823

Kellen V. 2017. The Origins of Innovation in the Edtech Ecosystem. Educause Review July/August. Available at:

https://er.educause.edu/articles/2017/7/the-origins-of-innovation-in-theedtech-ecosystem (Accessed on 10 January 2018.)

Layton J. 2013. How Massive Open Online Courses (MOOCs). Work 2 July 2013. HowStuffWorks.com. Available at:

https://people.howstuffworks.com/massive-open-online-coursesmoocs1.htm (Accessed on 9 April 2019.)

Mazur E. 2017. Rethinking Learning and Assessment with Eric Mazur. Available at: https://www.lde-studentsuccess.com/news/rethinking-learningand-assessment-with-eric-mazur (Accessed on 16 April 2019.)

Padayachee P., H. Johannes \& S. Wagner-Welsh 2017. Student Experience Informs a Supportive-environment Framework for Online Assessment in Moodle. Book of Abstracts. 1 $1^{\text {th }}$ Southern Hemisphere Conference on the Teaching and Learning of Undergraduate Mathematics and Statistics. 26Nov/01Dec 2017 Gramado, Brazil. Available at:

https://www.univates.br/media/evento/delta/book_of_abstracts_final_08-11.pdf (Accessed on 10 January 2018.)

Padayachee P., H. Johannes \& S. Wagner-Welsh 2018. Online Assessment in Moodle: A Framework for Supporting our Students. South African Journal of Higher Education 32,5211 - 235. Available at:

https://doi.org/10.20853/32-5-2599

Pappano L. 2012 The Year of the MOOC. New York Times November 2, 2012. Richardson, L.P., C.G. McGowan \& L.E.J. Styger 2018. A Quality Approach to Masters Education Using an Australian Case Study - A Reflection. 
Universal Journal of Educational Research 6,8: 1837 - 1847. Available at: http://www.hrpub.org/download/20180730/UJER29-19511740.pdf https://doi.org/10.13189/ujer.2018.060829

Salmon G. 2004. E-moderating: The Key to Teaching and Learning Online. Psychology Press.

Shepard, L.A. 2005. Linking Formative Assessment to Scaffolding. Educational Leadership November,63,3: 66 - 70.

Shepard, L.A. 2000. The Role of Assessment in a Learning Culture. Educational Researcher 29,7: 4 - 14 Issue published: October 1, 2000. https://doi.org/10.3102/0013189X029007004

Siemens G. 2004. Connectivism: A Learning Theory for the Digital Age. elearnspace (blog), December 12, 2004.

Siemens G. 2005. Connectivism: A Learning Theory for the Digital Age. International Journal of Instructional Technology \& Distance Learning 2,1. Available at:

http://www.itdl.org/journal/jan 05/article01.htm (Accessed on 30 January 2018.)

Siemens G. 2006. Connectivism. Learning Theory or Pastime for the Selfamused? Available at: https://altamirano.biz/conectivismo.pdf (Accessed on 9 April 2019.)

The HeraldLive 10 January 2017. Students-struggle-exams-deferred-feesmust-fall-protests. Available at:

https://www.sowetanlive.co.za/news/2017-01-10-students-struggle-withexams-deferred-because-of-fees-must-fall-protests/ (Accessed on 10 January 2018.)

Weller M. 2018. Twenty Years of Edtech. Educause Monday, July 2, 2018. Available at:

https://er.educause.edu/-/media/files/articles/2018/7/er184101.pdf (Accessed on 9 April 2019.)

Xiong, Y. \& H.K. Suen 2018. Assessment Approaches in Massive Open Online Courses: Possibilities, Challenges and Future Directions. Published online: 6 March 2018. Internal Review of Education 64: 241 263. https://doi.org/10.1007/s11159-018-9710-5

Zhu, M., C.J. Bonk \& A.R. Sari 2018. Instructor Experiences Designing MOOCs in Higher Education: Pedagogical, Resource, and Logistical Considerations and Challenges. Online Learning Journal 22,4: 203 - 241. https://doi.org/10.24059/olj.v22i4.1495 
\#FeesMustFall: Changing the Landscape of e-Assessment

\author{
Hermien Johannes \\ Instructional designer \\ HEADS \\ Nelson Mandela University \\ Port Elizabeth \\ hermien.johannes@mandela.ac.za
}

Simon Goldstone

Head: Digitally Enhanced Learning, Teaching \& Assessment (DELTA)

Embury

SimonG@embury.ac.za 